\title{
A palynological study of environmental changes and their implication for prehistoric settlement in the Ilan Plain, northeastern Taiwan
}

\author{
Shu-Fen Lin • Tseng-Chieng Huang • Ping-Mei Liew • \\ Su-Hwa Chen
}

Received: 1 October 2005 / Accepted: 7 April 2006 / Published online: 27 October 2006

(C) Springer-Verlag 2006

\begin{abstract}
Pollen records from two sediment cores taken from Ilan Plain, northeastern Taiwan provide new insights into the environmental and cultural history of the last 4200 years. The record indicates a relatively warm climate at around $4200 \mathrm{cal}$ B.P. The environmental conditions would have been suitable for people whose settlements and activities were mainly in the littoral zone during this period. However, at ca. 3800 cal B.P., elements tolerant of brackish water dominated the vegetation, indicating that the environment was influenced by marine incursion. The remarkable increase in wetland flora suggests the presence of widespread marshlands thereafter. It is quite conceivable that settlement movement from the fluvial plain to hills between 3800 and $2400 \mathrm{cal}$ B.P. can be correlated with the environmental changes in lowlands. A conspicuous gap in the archaeological sequence between 2400 and 1300 cal B.P. corresponds chronologically with a period of heavy rainfall or frequent typhoons
\end{abstract}

\footnotetext{
Communicated by F. Schlütz

S.-F. Lin $(\bowtie)$

Institute of History and Philology, Academia Sinica,

Taipei, Taiwan, ROC

e-mail: afen@mail.ihp.sinica.edu.tw

T.-C. Huang

Institute of Plant Biology, National Taiwan University,

Taipei, Taiwan, ROC

e-mail: huangtc@ntu.edu.tw

P.-M. Liew

Institute of Geosciences, National Taiwan University,

Taipei, Taiwan, ROC

e-mail: liewpm@ntu.edu.tw

S.-H. Chen

Department of Life Science, National Taiwan University,

Taipei, Taiwan, ROC

e-mail: suchen@ntu.edu.tw
}

as indicated by the aggradational episode in the Lanyang drainage basin as well as the flourishing of Alnus forests. The persistence of frequent landslides and climate deterioration would have had a dramatic impact on ancient humans and led to abandonment of the settlements. By $1300 \mathrm{cal}$ B.P. a lowland flora is widespread indicating a shift from a marsh to a terrestrial environment in response to a well-developed fluvial plain. Decrease of landslides and the amelioration in climate could have advantages to human activities again. However, both the pollen and archaeological records indicate that intensive colonisation had a profound effect upon the vegetation within the Ilan region about 400 years ago.

Keywords Pollen analysis · Late Holocene . Archaeological site $\cdot$ Vegetation history $\cdot$ Taiwan

\section{Introduction}

In an effort to understand the paleoenvironment and its role in social processes, especially the rise and fall of former civilisations, more and more interdisciplinary studies have been carried out in recent years (Ortloff and Kolata 1993; Curtis et al. 1996; Binford et al. 1997; Grosjean et al. 1997; Wu and Liu 2004; Yasuda et al. 2004; Pederson et al. 2005). Previous studies have shown that changes in the environment are often an important factor in population dislocation, urban abandonment and state collapse (Shimada et al. 1991; Weiss et al. 1993; Hodell et al. 1995; Abbott et al. 1997; Stanley et al. 1999; Cullen et al. 2000; Yu et al. 2000; deMenocal 2001; Hoelzmann et al. 2001; Polyak and Asmerom 2001; Weiss and Bradley 2001; Bishop et al. 2003; Compton and Franceschini 2005). High-resolution paleoclimate and paleoenvironmental records thus become imperative for understanding ancient cultural changes. 


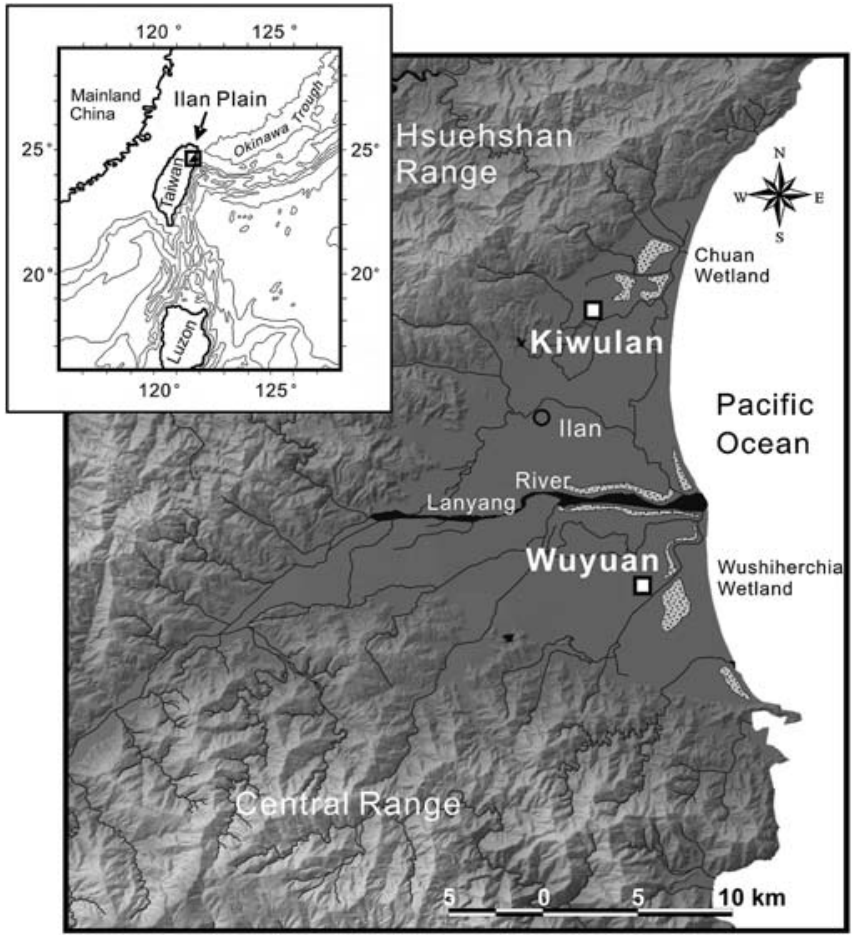

Fig. 1 Geographical setting of the Ilan Plain (upper map) and the locations of the Wuyuan and Kiwulan sites (map on right). Dotted pattern areas on the map on the right indicate wetlands scattered around the littoral zone

The Ilan Plain, an alluvial delta in north-eastern Taiwan (Fig. 1), is situated in a geologically critical position-the southwest tip of the Okinawa Trough (Suppe 1984; Letouzey and Kimura 1986; Yeh et al. 1989; Liu 1995a). It is characterised by an unusually high sedimentation rate (max. $>10 \mathrm{~mm} / \mathrm{yr}$ ) thus affording a unique opportunity to study continuous environmental history in detail. Postglacial vegetation history and climate in Taiwan have been studied through pollen analyses since the 1960s (Tsukada 1966, 1967; Chung and Huang 1972a,b; Chung et al. 1973; Huang and Huang 1977a,b; Kuo 1994; Liew and Huang 1975,1994; Liew et al. 1997,1998; Kuo and Liew 2000; Liew and Hsieh 2000; Liew and Chung 2001). However, most of the studies come from highland lakes, whereas those of the lowlands are less understood. They also take less account of the impact of climate and environment changes on human activities in the anthropogenic era due to the lack of direct palynological evidence (except that of Huang and Tsang 1976).

A long habitation history, going back to the Neolithic and Iron Age, is well supported by archaeological remains in the Ilan region (Liu et al. 2002; Chen and Chiu 2004). The archaeological evidence clearly indicates profound changes in settlement patterns and the presence of different human races during the prehistoric past (Liu 1995b, 2000; Liu et al. 2001). In this paper we present pollen records for the late Holocene from two sites, Wuyuan and Kiwulan, in south- ern and northern parts of the Ilan Plain respectively (Fig. 1). Based on these data, we try to reconstruct across recent millennia the climatic and environmental changes which probably affected the development of prehistoric cultures in this region.

\section{Study area}

The Ilan Plain is an almost equilateral triangular alluvial delta, facing the Pacific Ocean to the east and surrounded by steep mountains to the northwest and southwest. Almost half of its very flat terrain is below $20 \mathrm{~m}$ in elevation. A number of rivers, of which the Lanyang River system is the most important, contribute sediments to the plain. In the coastal region scattered sand dunes impede the passage of the rivers, forming a series of wetlands behind the dunes from north to south. These wetlands are frequently invaded by seawater at flood tide as they are only $1-2 \mathrm{~m}$ above sea level. Today they form a sensitive ecosystem.

The climate of the region is humid and subtropical. It is strongly influenced both by Asian summer and winter monsoons. Even though derived from cooler and drier areas of the Asian mainland, the winter monsoons become vapour-saturated as they pass over the ocean before arriving in Taiwan. The funnel-shaped topography of the plain further enhances the rainfall. Thus in Taiwan the Ilan region is famous for high precipitation, especially in autumn and winter when the winter monsoons prevail (Chiang 1995).

According to the records from A.D. 1936 to 2003 from the Ilan Weather Station, the July and January mean temperatures are $28.2^{\circ} \mathrm{C}$ and $15.9^{\circ} \mathrm{C}$ respectively. Annual precipitation is very high (ca. $2760 \mathrm{~mm}$ ), with the greatest amount in September, October and November (www.cwb.gov.tw, Central Weather Bureau). Thus there is almost never any drought throughout the year and sometimes even floods during autumn.

The natural vegetation of the lowlands and hills in Ilan is a subtropical evergreen rain forest although the main component of the vegetation type is highly dependent on topography and altitude (Su 1984). The vegetation of the surrounding mountains consists of subtropical to warm temperate forests dominated by Lauro-Fagaceae elements common in the Castanopsis-Machilus Zone (Chen 2000a). Among the characteristic trees are various hard wood species like Castanopsis cuspidata var. carlesii form. sessilis, Castanopsis uraiana, Machilus japonica var. kusanoi, Ardisia sieboldii, Ficus fistulosa var. fistulosa, Engelhardia roxburghiana, Cyclobalanopsis pachyloma, Elaeocarpus japonicus, Bischofia javanica and Lagerstroemia subcostata. In the very recent past, stands of Alnus formosana were found, but only in very small isolated enclaves in the riverine areas and alluvial fans of the plain. Today, much of the plain is under culti- 
Fig. 2 Lithology and age model for the Wuyuan core. Age model based on 5 calibrated radiocarbon dates (see Table 1 for details). Calculation of sedimentation rates assumes constant accumulation between dated layers

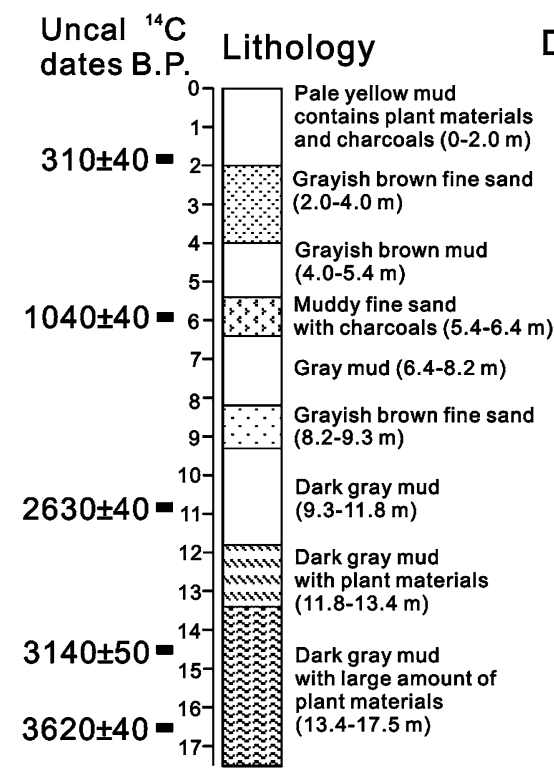

Wuyuan Profile

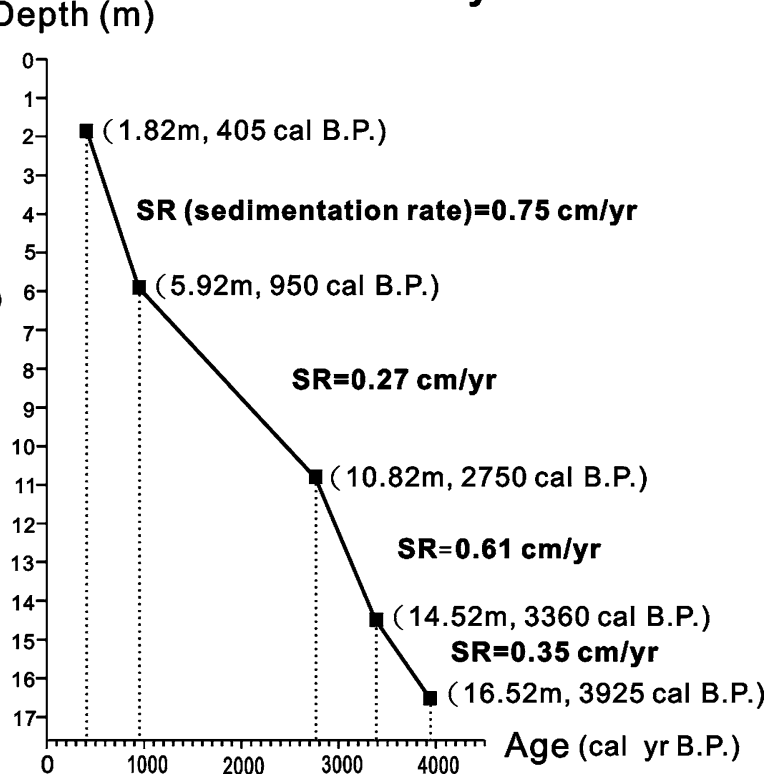

vation (mostly rice) or covered by herbaceous plants and cultivated trees. Shrubs such as Barringtonia racemosa and Cephalanthus naucleoide are scattered on the river banks. The main components of the coastal marshland flora are Gramineae, Cyperaceae, and aquatics such as Typha orientalis (Kuo 1993).

\section{Description of the sites}

The Wuyuan site (3.2 $\mathrm{m}$ a.s.l.) is situated in the southern part of the Ilan Plain near the Wushiherchia Wetland. It is an archaeological site that appears to have been settled at about 400 years ago (Huang 1998). A core of $190 \mathrm{~m}$ in depth was recovered by the Central Geological Survey in the year 2000 for the Project "Groundwater Monitoring Network in Taiwan". The lower $150 \mathrm{~m}$ of this core are primarily transgressive deposits after the Last Glacial Maximum and, based on stratigraphy and radiocarbon dates, the upper $40 \mathrm{~m}$ are more recent terrestrial sediments (Chen 2000b).

The Kiwulan site (at about sea level) is situated in the northern part of the plain near the Chuan Wetland. We sampled along the profile of an archaeological excavation performed by the Department of Anthropology, National Taiwan University. The upper part $(4.5 \mathrm{~m})$ of the profile was collected directly from the side of the trench while the lower $2.5 \mathrm{~m}$ of the sediments were sampled using a drilling corer. Chronologically, the Kiwulan Archaeological site was occupied during the Iron Age (ca. 1300-900 cal B.P. and ca. 700-400 cal B.P.; Chen and Chiu 2004). In the profile studied, the upper cultural horizon is at $0.20-0.30 \mathrm{~m}$ in depth and the lower cultural horizon at $1.05-1.15 \mathrm{~m}$. The profile comprises sediments of fluvial deposits and wetland. Mixtures of shells such as Cerithidea, Ruditapes and Meretrix in the lower part suggest a brackish to freshwater environment with some marine influence. Abundant leaf fragments of Phragmites were found at depths from 3.9-4.7 $\mathrm{m}$ in the profile.

\section{Materials and methods}

The lithologies of the Wuyuan and Kiwulan profiles are illustrated in Figs. 2 and 3 respectively. The samples from the Wuyuan site cover the uppermost $17.5 \mathrm{~m}$, and are muddy to fine sand sediments that were deposited in the last 4200 years. Samples of $5 \mathrm{~cm}$ depth, representing approximately 10-20 years each, were extracted at $25 \mathrm{~cm}$ intervals (ca. 50-100 years) from the top $4.0 \mathrm{~m}$ and at $10 \mathrm{~cm}$ intervals (ca. 20-40 years) from depths 4.0 to $17.5 \mathrm{~m}$. Ninety-four samples of $2 \mathrm{ml}$ each were selected for pollen analysis.

The samples from the Kiwulan site were deposited in the recent 2700 years. Samples of $5 \mathrm{~cm}$ depth, representing approximately 10-40 years each, were taken at 10 -cm intervals (20-80 years) throughout the $7 \mathrm{~m}$ profile and sixty-seven samples were selected for pollen analysis.

Samples were prepared according to a procedure slightly modified from Moore et al. (1991), involving treatments with hydrochloric acid, potassium hydroxide, sodium pyrophosphate and hydrofluoric acid. For each sample, more than 200 non-aquatic pollen grains were counted except for samples with very low pollen counts. When samples 
Fig. 3 Lithology and age model for the Kiwulan core. Age model based on 4 calibrated radiocarbon dates (see Table 1 for details) and the estimated ages of cultural horizons based on the archaeological inventories

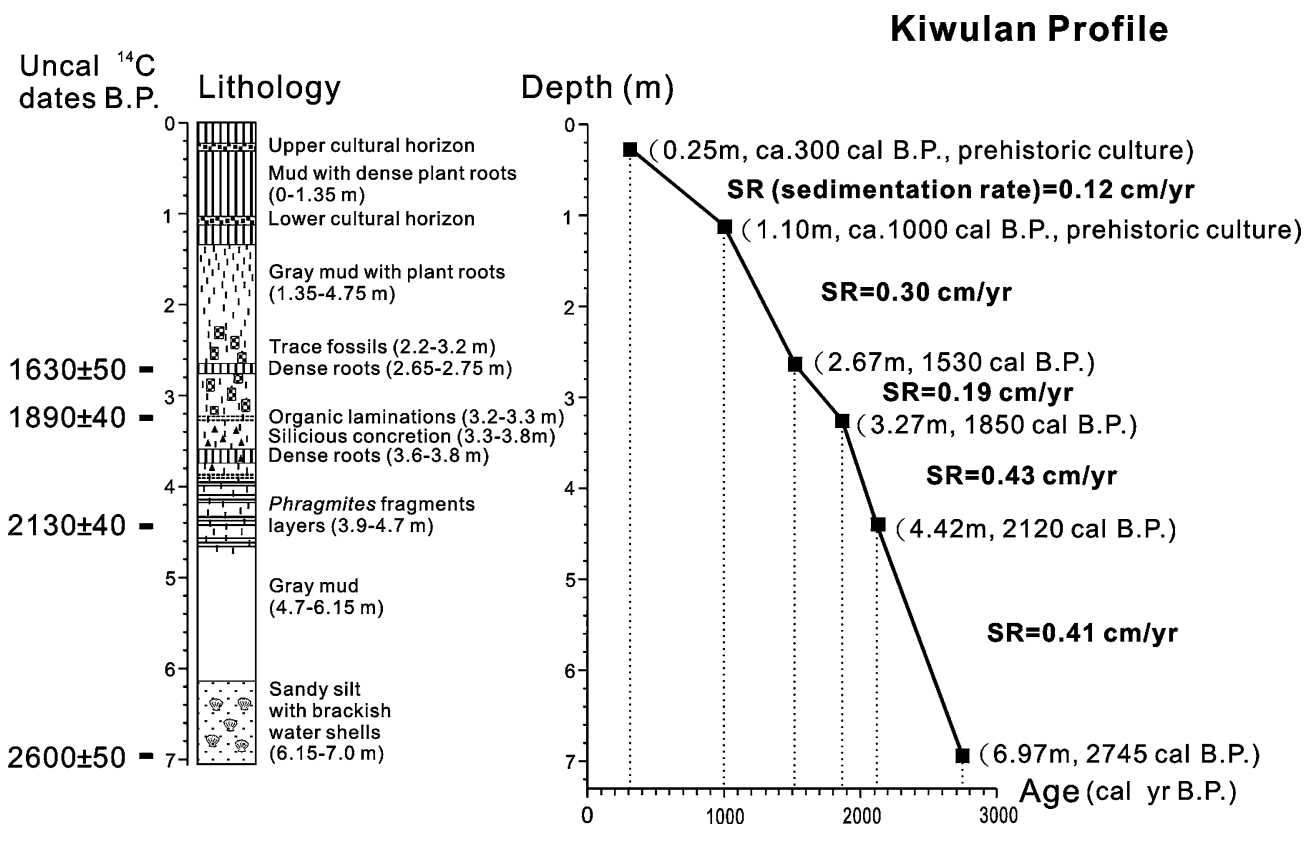

contain large amounts of fern spores, a minimum of 500 grains of pollen and spores was counted. The taxonomic nomenclature in the pollen diagrams followed the published keys from Huang (1972, 1981), Thanikaimoni (1987), Moore et al. (1991), and Chen and Wang (1999). Flora of Taiwan, 2nd edition (Huang et al. 1993-2003) was used as a nomenclatural reference for modern flora. It was difficult to distinguish with certainty the pollen taxon Cyclobalanopsis from Quercus and the taxon Castanopsis from Pasania and Lithocarpus in the samples because of their close morphological similarity. In this study, Fagaceae pollen is divided into Cyclobalanopsis-type (including Quercus) and Castanopsis-type (including Pasania and Lithocarpus) taking into account their ecological significance in the Ilan region.

Percentages of terrestrial taxa were calculated based on the sum of terrestrial plant pollen. The percentages for mangrove and aquatic taxa were calculated using terrestrial pollen added to the sum of mangrove and aquatic pollen. Spore percentages are based on the sum of spores and terrestrial, mangrove and aquatic pollen. Percentage calculations and construction of the diagrams were performed using the Tilia and TGView programs (Grimm 2004, 2005).

The chronology was based on 9 AMS dates covering a time-span of the last 4200 years (Table 1). Radiocarbon dates were calibrated using the CALIB rev.4.4.1 program (Stuiver et al. 1998). The age constraint of the cultural horizons estimated from archaeological dates in the Kiwulan profile was adopted in this study. Sediment accumulation rates were calculated using linear interpolation between the cal ${ }^{14} \mathrm{C}$ dates.

\section{Results}

Pollen of more than 100 taxa including either families or genera was identified in samples from the Wuyuan and Kiwulan cores. These include major trees of Fagaceae (mainly
Table 1 Radiocarbon and calibrated ages for the Wuyuan and Kiwulan profiles; calibration using CALIB 4.4.1 (Stuiver et al. 1998)

\begin{tabular}{cllll}
\hline Laboratory code & Depth $(\mathrm{m})$ & ${ }^{14} \mathrm{C}$ age $(\mathrm{yr}$ B.P. $)$ & Calibr. Age, $1 \sigma(\mathrm{yr}$ B.P. $)$ & Material dated \\
\hline Wuyuan profile & & & & \\
Beta-176348 & $1.80-1.85$ & $310 \pm 40$ & $405(455-305)$ & Charcoal \\
Beta-176349 & $5.90-5.95$ & $1040 \pm 40$ & $950(970-930)$ & Charcoal \\
WK-15412 & $10.80-10.85$ & $2630 \pm 40$ & $2750(2770-2745)$ & Plant fragments \\
Beta-176351 & $14.50-14.55$ & $3140 \pm 50$ & $3360(3435-3270)$ & Plant fragments \\
Beta-146837 & $16.50-16.55$ & $3620 \pm 40$ & $3925(3980-3870)$ & Wood \\
Kiwulan profile & & & & \\
WK-12120 & $2.65-2.70$ & $1630 \pm 50$ & $1530(1560-1420)$ & Charcoal \\
WK-12121 & $3.25-3.30$ & $1890 \pm 40$ & $1850(1875-1745)$ & Plant fragments \\
WK-12122 & $4.40-4.45$ & $2130 \pm 40$ & $2120(2285-2045)$ & Phragmites \\
WK-12123 & $6.95-7.00$ & $2600 \pm 50$ & $2745(2750-2735)$ & fragments \\
\hline
\end{tabular}




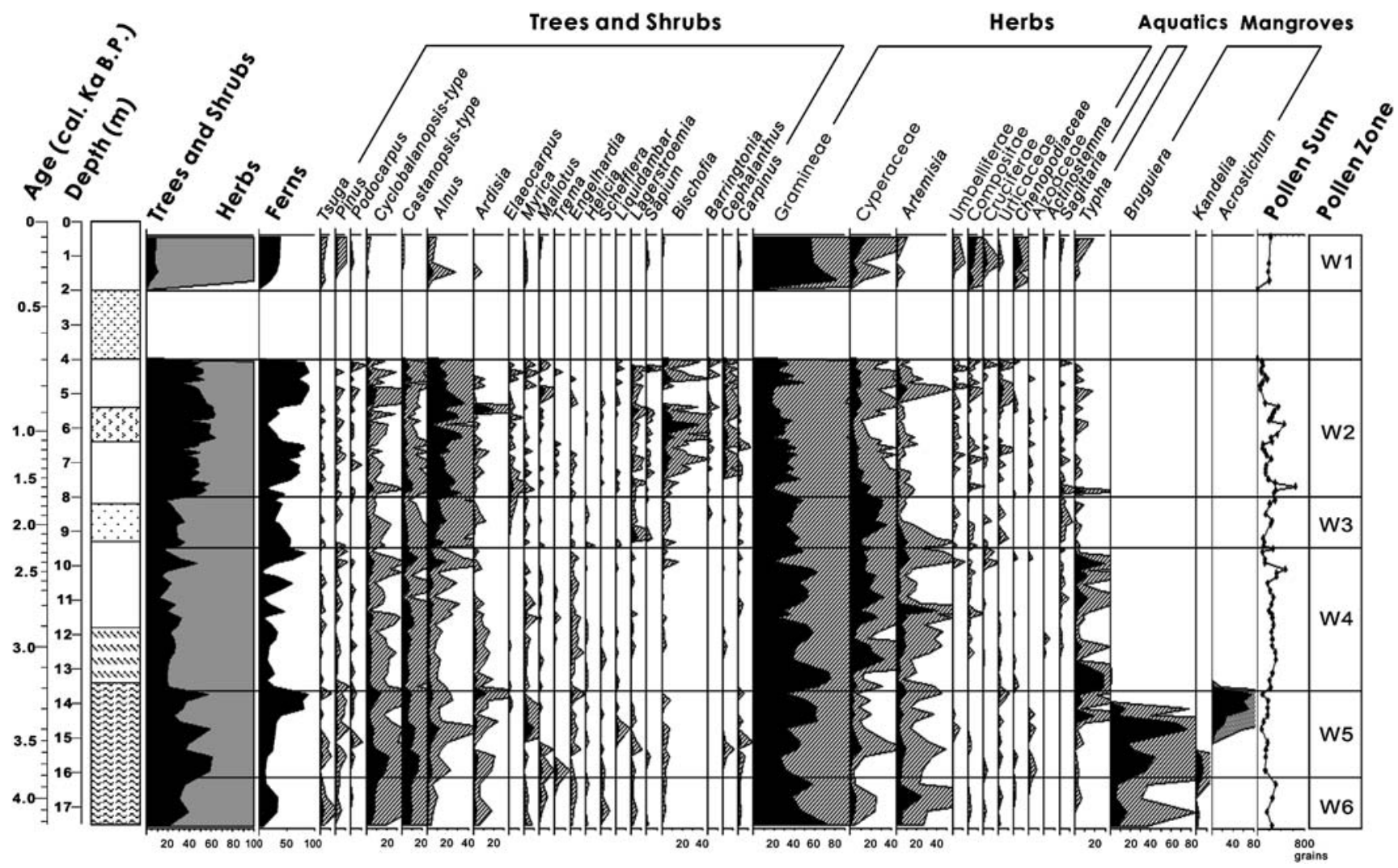

Fig. 4 Pollen percentage diagram of selected taxa from the Wuyuan site. Calculations of the terrestrial taxa based on the sum of pollen of all plants without mangrove and aquatic taxa. Percentages of man- grove and aquatic taxa based on the sum of terrestrial, mangrove and aquatic pollen grains. Spore percentages based on the sum of spores and terrestrial, mangrove and aquatic pollen. Exaggeration $\times 5$
Castanopsis, Pasania, Cyclobalanopsis and Quercus), Alnus, Helicia, Ardisia, Myrica, Elaeocarpus, Engelhardia, Bischofia, Lagerstroemia, Cephalanthus, Barringtonia and major herbs of Gramineae, Cyperaceae, Artemisia, other Compositae, Umbelliferae, Cruciferae and Chenopodiaceae. Diagrams of pollen percentages were drawn according to the composition and quantity of major pollen taxa present in samples (Figs. 4 and 5).

Wuyuan site

On the whole, the percentages of tree pollen are relatively low, while herb pollen and fern spores are more abundant in the Wuyuan site. The sediments between 2.0 and $4.0 \mathrm{~m}$ in depth are poor in pollen due to oxidation and because the sediments are too coarse for pollen preservation. The pollen diagrams, spanning the last 4200 years, are divided into six zones as shown in Fig. 4.

Zone W6 (17.5-16.1 m; ca. 4200-3800 cal B.P.)

This zone is characterised by abundant herb pollen and fern spores. The herb pollen (mainly Gramineae, Artemisia and
Cyperaceae) comprises about $70 \%$ of the terrestrial pollen, and fern spores account for $30 \%$ of the total of all pollen and spores. This assemblage also indicates some broad-leaved, evergreen trees such as Cyclobalanopsis, Castanopsis, Ardisia, Myrica, Engelhardia, Schefflera and Alnus growing on higher ground. The percentages of lowland taxa such as Bischofia, Lagerstroemia and Cephalanthus are low.

Zone W5 (16.1-13.6 m; ca.3800-3200 cal в.P.)

This zone is marked by a high percentage of the mangrove taxon Bruguiera (20-75\% of all pollen) in the lower section, which is then replaced by spores of Acrostichum (up to $80 \%$ of the sum of all pollen and spores) in the upper section. Pollen from arboreal taxa appears to be relatively common and diverse, whilst the percentages of lowland taxa are low. It is notable that the percentage of Typha increases in the upper part of this zone.

Zone W4 (13.6-9.45 m; ca. 3200-2250 cal B.P.)

This zone is characterised by the remarkable increase in the pollen of local wetland vegetation, especially Cyperaceae 


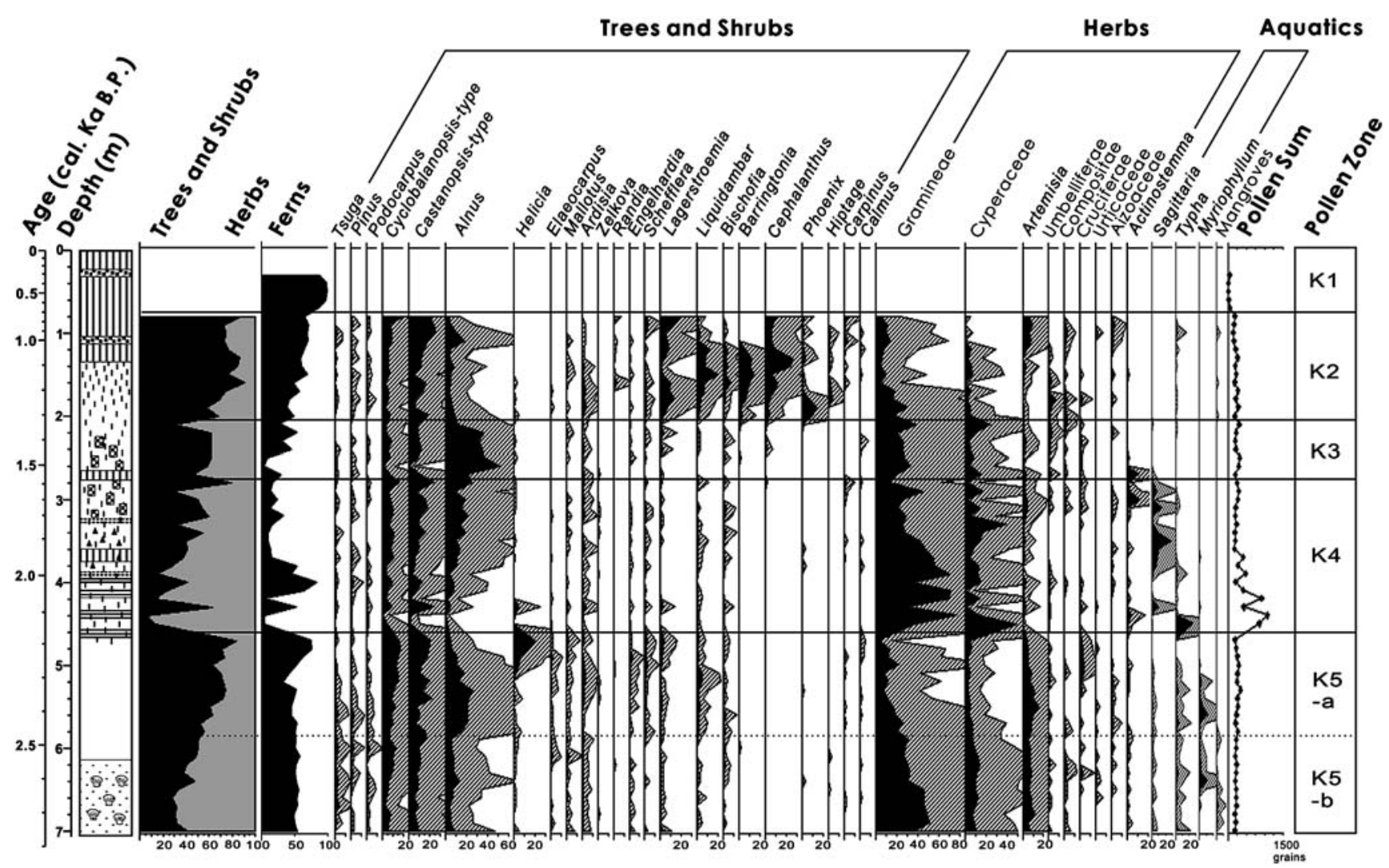

Fig. 5 Pollen percentage diagram of selected taxa from the Kiwulan site. Percentage calculation as for Fig. 4. Exaggeration $\times 5$

and the freshwater aquatic taxon Typha. The mangrove and taxa tolerant of brackish water that dominated in the former zone are no longer present. Pollen taxa common in the lowlands remain rare. Variations in percentages of fern spores, accompanied by a slight increase in Alnus pollen grains, occur in the upper part of this zone.

\section{Zone W3 (9.45-8.0 m; ca. 2250-1700 cal B.P.)}

This zone is marked by the common occurrence of Alnus, accounting for $10-17 \%$ of the terrestrial pollen grains. Although remaining rare, the lowland taxa such as Bischofia and Lagerstroemia are present. Typha pollen declines although local wetland herbs such as Gramineae and Cyperaceae remain significant. These vegetation changes coincide with the abrupt change of sediments from wetland clays to fine riverine sands.

Zone W2 (8.0-4.0 m; ca. 1700-700 cal в.P.)

This zone begins with an obvious increase of tree pollen to $50-60 \%$ of all land plants. Alnus is the predominant contributor, accompanied by Cyclobalanopsis-type, Castanopsis-type, Ardisia, Elaeocarpus, Lagerstroemia, Sapium, Bischofia and Cephalanthus. In contrast to the pre- vious zones, the pollen of lowland trees such as Bischofia, Barringtonia and Cephalanthus rises obviously and reaches a maximum. In addition the proportion of wetland vegetation, especially Cyperaceae pollen, decreases.

\section{Zone WI (2.0-0 m; ca. 430 cal B.P. to recent)}

This zone is marked by a sharp decline in tree pollen and a large increase in herbaceous pollen. Alnus pollen decreases quickly to less than $5 \%$ of the total terrestrial pollen sum. The proportion of Gramineae pollen increases greatly to 55-80\% accompanied by a rise in other weeds (e.g., Umbelliferae, Compositae, Cruciferae and Chenopodiaceae).

Kiwulan site

In the pollen sequence from the Kiwulan site, five pollen zones were delimited during the last 2700 years (Fig. 5).

\section{Zone K5 (7.0-4.6 m; ca. 2770-2170 cal B.P.)}

This zone is characterised by abundant herb pollen, accounting for $70 \%$ of the terrestrial pollen sum in the lowest part but decreasing upward to $30 \%$. Pollen of arboreal elements, 
dominated by Cyclobalanopsis-type, Castanopsis-type and Alnus progressively increases up the section. The percentages of lowland pollen taxa are at low. Freshwater aquatic taxa, such as Myriophyllum, occur sporadically. Two subzones are recognised as $\mathrm{K} 5-\mathrm{b}$ and $\mathrm{K} 5-\mathrm{a}$ in ascending order. Subzone K5-b (7.0-5.85 m; ca. 2770-2480 cal B.P.) is dominated by the pollen of Gramineae, Cyperaceae and Artemisia, accompanied by the pollen of Myriophyllum and a little mangrove pollen. Brackish water shells are found in sediments of this subzone. Subzone K5-a (5.85-4.6 m; ca. 2480-2170 cal B.P.) is characterised by the sharp increase in Alnus pollen. The percentage of Helicia pollen increases obviously in the uppermost part of this subzone, whereas Alnus declines.

Zone K4 (4.6-2.7 m; ca. 2170-1580 cal в.P.)

This zone is distinguished by the dominance of the pollen of local wetland flora, Gramineae, Cyperaceae and the common occurrence of freshwater aquatic plants such as Typha and Sagittaria. The Alnus pollen percentage increases progressively from $3 \%$ to $25 \%$ upwards through the zone. Helicia pollen decreases significantly. Common lowland pollen taxa remain rare.

Zone K3 (2.7-2.05 m; ca. 1580-1320 cal в.P.)

This zone is characterised by the highest value in the entire profile of Alnus pollen, accounting for 30-50\% of the sum of terrestrial plant pollen. Gramineae and Cyperaceae pollen percentages are moderately high, whereas the percentages of aquatic plants are low compared with the previous zone. Pollen of lowland taxa is present at very low values.

\section{Zone K2 (2.05-0.75 m; ca. 1320-710 cal в.P.)}

This zone is characterised by the pollen of trees and shrubs from lowlands, in particular Lagerstroemia, Liquidambar, Bischofia, Barringtonia, Cephalanthus and Phoenix becoming more prominent and important. The pollen of Alnus shows a significant decrease (from $40 \%$ to $<10 \%$ of the terrestrial pollen sum) with respect to its percentage in the previous zone. The percentages of herbaceous pollen, mainly Gramineae and Cyperaceae, are also lower than in the former zone.

\section{Zone $K 1(0.75-0 \mathrm{~m}$; ca. $710 \mathrm{cal}$ B.P. to recent)}

This zone is remarkable for the dominance of fern spores, which make up around $85 \%$ of the sum of all pollen and spores. Pollen grains are very rare or even absent throughout this zone and omitted in Fig. 5. The low abundance of pollen grains in this zone is probably the result of selective preservation favouring the relatively resistant forms like fern spores in the oxidation process during deposition. No interpretation is attempted since the assemblage could be limited by the fossilisation process rather than the composition of the palaeovegetation.

\section{Discussion}

\section{Palaeoenvironment}

The pollen diagrams from the Wuyuan and Kiwulan sites reveal the evolution of palaeovegetation and palaeoenvironment in the Ilan region. By ca. 4200 cal B.P., montane forest around the Ilan Plain was dominated by broad-leaved evergreen trees such as Cyclobalanopsis, Quercus, Castanopsis, Pasania, Lithocarpus, Ardisia, Myrica, Engelhardia, Schefflera and Alnus (Zone W6) similar to the present-day forest. A herbaceous flora, mainly Gramineae and Artemisia, dominated in lowlands. The pollen record shows a relatively warm period probably prevailed between 4200 and 3800 cal B.P.

At approximately 3800 to 3200 cal B.P. (Zone W5), the flourishing of Bruguiera and Acrostichum suggests that mangrove and taxa tolerant of brackish water dominated at the Wuyuan site. Both Bruguiera and Acrostichum are not found in Ilan today. Bruguiera gymnorrhiza was reported to occur in southern Taiwan forty years ago, but is now extinct (Hsieh 1984). Acrostichum aureum, which appears locally in southeastern Taiwan today, occurred in northern Taiwan about 120 years ago (Kuo 2001). A plausible explanation is that they were previously more widespread, and could have been a dominant component at Wuyuan prior to ca. $3200 \mathrm{cal}$ B.P. It is probable that before 3200 cal B.P., the site was situated either in a brackish to freshwater environment with some marine influence, or was closer to sea than at present. A local marine transgression and the subsequent regression occurred in the Ilan region at around 3800 years ago.

Although marine regression took place at about $3200 \mathrm{cal}$ B.P., a fairly wet and unstable environment existed in lowlands between 3200 and 2250 cal B.P. The lowlands were occupied largely by marshlands and river systems, as revealed by the abundance of Gramineae, Cyperaceae and an aquatic pollen flora (Zones W4 and K5). The disappearance of Bruguiera and Acrostichum implies an eastward shift of the coastline in the vicinity of Wuyuan. Nevertheless, the occurrence of shells of brackish water species, accompanied by a freshwater aquatic flora and mangrove probably indicates a fluvial environment near estuaries at the Kiwulan site between 2770 and 2480 cal B.P. (Subzone K5-b).

By ca. 2250 cal B.P., the remarkable increase in Alnus suggests its progressive expansion in nearby highlands (Zones W3, K4 and K3). Chronologically, the period of major presence of Alnus coincides approximately with a widespread 
Table 2 The cultural series, chronology of occupation and the distribution of settlements in the Ilan region

\footnotetext{
${ }^{a}$ Quoted from Liu (1995b).

${ }^{b}$ From the Kiwulan site (Chen and Chiu 2004).

${ }^{c}$ From the Wanshan site (Liu et al. 2002).

${ }^{d}$ Originated from the Tachuwei site (Liu et al. 2001).
}

\begin{tabular}{lll}
\hline Cultural Series & Age (cal B.P.) & Distribution of settlements \\
\hline $\begin{array}{l}\text { Iron Age (later Stage) } \\
\text { Shihsanhang Culture }\end{array}$ & $600-^{a}$ & Alluvial fans, riverine and littoral areas \\
$\quad$ Chiushe Type & & \\
$\begin{array}{l}\text { Iron Age (earlier Stage) } \\
\text { Shihsanhang Culture }\end{array}$ & $1300-700^{b}$ & Riverine areas, coastal dunes \\
$\quad \begin{array}{l}\text { Puluowan Type } \\
\text { Hiatus of archaeological sequence }\end{array}$ & & \\
$\begin{array}{l}\text { Late Neolithic Age } \\
\quad \text { Wulaokeng Series }\end{array}$ & $3900-2400^{c}$ & Inland hills \\
$\begin{array}{l}\text { Middle Neolithic Age } \\
\text { Sinchen Series }\end{array}$ & $4200-3700^{d}$ & Palaeodunes, hills around plain \\
& & \\
\hline
\end{tabular}

aggradation of terraced fans in the Lanyang drainage basin from 2150 to 1350 cal B.P. (Chen 1996; Chyi et al. 1998; Liew and Hsieh 2000). The increase in Alnus is explained as being due to frequent landslides in mountainous areas bordering the Ilan Plain, since Alnus forests are widespread in landslide fields and are considered to represent a pioneer flora. It possibly suggests frequent typhoons or heavy precipitation during this period.

The decline of the aquatic flora at the Wuyuan site from 2250 to1700 cal B.P. (Zone W3) probably indicates the shrinking of water bodies in the area although the local wetland plants remained significant. However, the pollen record from the Kiwulan site implies that there water bodies expanded between 2170 and 1580 cal B.P. (Zone K4) and shrank thereafter (Zone K3).

At around 1320 cal B.P. (or possibly 1500 cal B.P. from the record at the Wuyuan site), the increase in riverine flora Cephalanthus and Barringtonia reflects a terrestrial environment. The expansion of lowland vegetation may be a response to the progressive development of the fluvial plain (Zones W2 and K2). In spite of its common occurrence in the Wuyuan profile, the decline of Alnus at the Kiwulan site probably indicates climate amelioration and the diminishing of landslide frequency from ca. 1320 cal B.P.

About 400 years ago, profound human impact upon the vegetation may have occurred within the Ilan region as indicated by the decrease of forest elements and the dominance of herbaceous plants (Zone W1). Significant forest clearance and settlement occurred as shown by the pollen data.

\section{Cultural series and environmental changes}

More than 70 archaeological sites have been reported in the Ilan region (Liu 2000). They indicate an intensive prehistoric occupation of the region during the late Holocene (Liu et al. 2001, 2002; Chen and Chiu 2004). Based on pottery types, at least four cultural series can be distinguished chronologically. They are the Sinchen Series (Middle Neolithic), the Wulaokeng Series (Late Neolithic), the Shihsanhang Culture Puluowan Type (earlier stage in Iron Age) and the Shihsan- hang Culture Chiushe Type (later stage in Iron Age). Despite some inconsistencies in dating, the resulting blurred picture gives a general indication of the chronological position of the archaeological series (Table 2).

The distribution of the archaeological sites turned out to be very diverse. In the Middle Neolithic, the sites were located in the sand dunes along the palaeo-shoreline or on the hills around the plain (Fig. 6a). The remains provide a record of human utilisation of coastal resources during this period. However, the inhabitants began to move to the hills around 3800 cal B.P. although settlement in lowlands ought generally to have been the first choice. The sites were located in what were inland hills surrounding the plain in the Late Neolithic (Fig. 6b). It is not surprising that there is no evidence for extensive fishing by the Late Neolithic people. Their livelihood was mainly cultivation and hunting.

There is a conspicuous gap in the archaeological record between 2400 and 1300 cal B.P. However, at around $1300 \mathrm{cal}$ B.P., a different clan occupied the Ilan Plain in the earlier part of the Iron Age. Sites of this period were located in riverine areas and among coastal dunes (Fig. 6c). The prehistoric diets relied heavily on estuarine fish and molluscs. In the later part of the Iron Age, numerous sites were recorded across the Ilan Plain, stretching from the alluvial fans into the littoral zone (Fig. 6d).

Taking the archaeological record of cultural change within the context of detailed and well-dated Holocene palaeoenvironmental records provides opportunities to examine how prehistoric societies responded to changes in environment. The pollen record from the Wuyuan site implies relatively warm conditions prevailing between 4200 and 3800 cal B.P. The climate would be suitable for people in the Middle Neolithic when their settlements were distributed mainly in littoral areas and their livelihood depended mainly on coastal resources.

However, around 3800 years ago the settlements in the lowlands were abandoned. The subsequent culture in the Late Neolithic was established in higher landscapes surrounding the plain between 3900 and 2400 cal B.P. The pollen record 

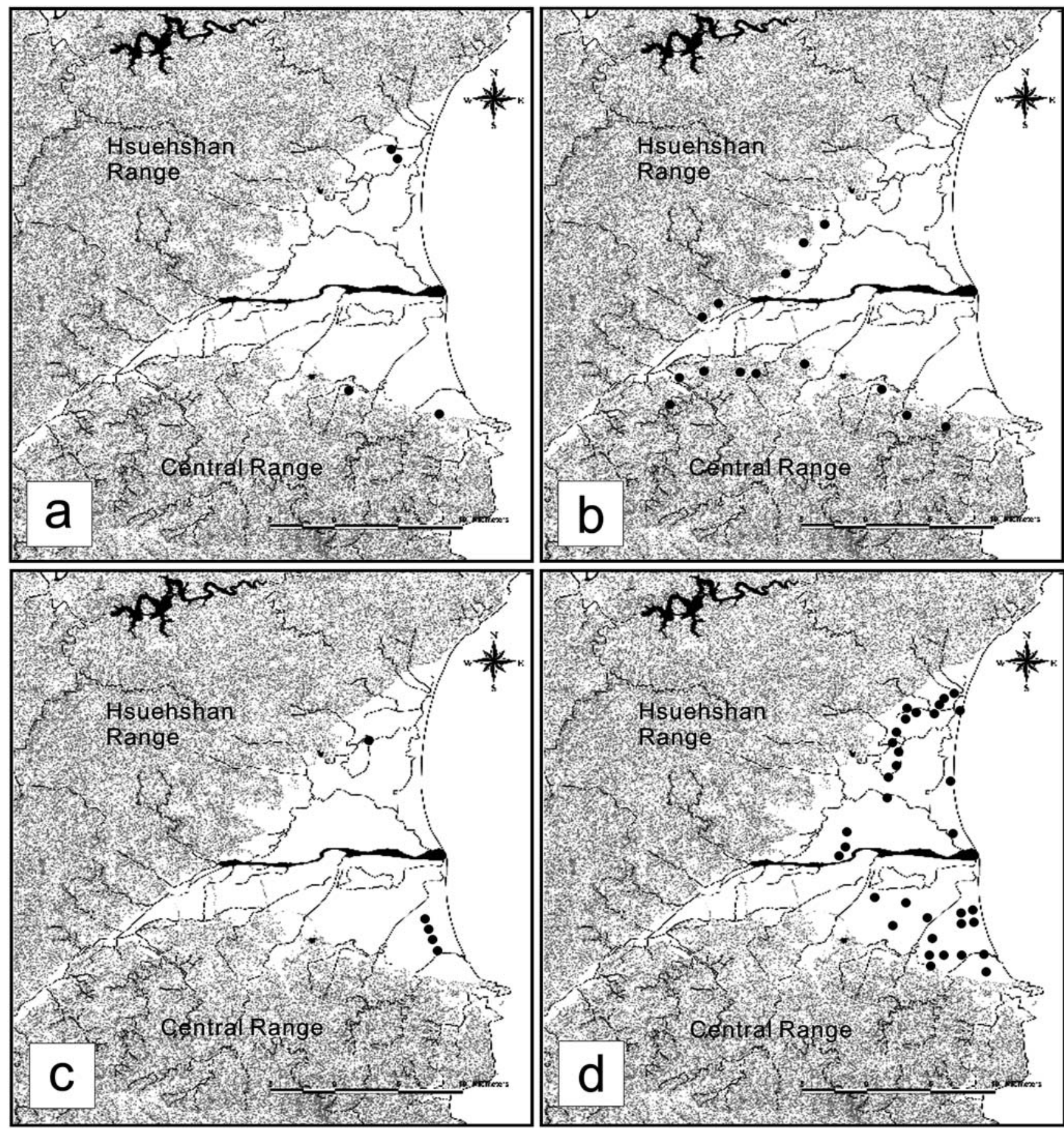

Fig. 6 Spatial distribution of archaeological sites of the different cultural series in the Ilan region (Liu 1995b). a Sinchen Series (Middle Neolithic), b Wulaokeng Series (Late Neolithic), c Shihsanhang Cul-

ture Puluowan Type (earlier stage in the Iron Age) and d Shihsanhang Culture Chiushe Type (later stage in the Iron Age)

documents a dramatic increase in mangrove and wetland flora which implies a short period of local marine transgression commencing at around 3800 cal B.P., followed by a fairly wet and unstable environment in the lowlands between 3200 and 2250 cal B.P. In addition, the level of the stratigraphic profile representing the abandonment of set-

tlement at the Tachuwei Archaeological site, attributed to the Middle Neolithic, is overlain by a thick $(\sim 40 \mathrm{~cm})$ accumulation of organic mud, suggesting a sudden shift to a wetland environment at ca. 3800 cal B.P. (Liu et al. 2001). It is quite conceivable that the population dislocation around 3900 to 2400 cal B.P. could be explained by the environmen- 
tal changes in the lowlands where they became unsuitable for human occupation.

Around 2400 years ago or later, the archaeological sequence was interrupted throughout the Ilan region. Taking into account the palaeoenvironmental changes and cultural history, the hiatus between 2400 and 1300 cal B.P. corresponds to a period of heavy precipitation or frequent typhoons. This is implied by the wide terraced fans at Lanyang River, as well as the thriving Alnus forests. It is reasonable to propose that the environmental instability, mainly frequent landslides or climate deterioration, would have had a dramatic impact on the settlements and led to the demise of the Late Neolithic occupation.

After the gap in the archaeological record, a different clan attributed to the earlier part of the Iron Age occupied the Ilan Plain from ca. 1300 cal B.P. The pollen record implies that the fluvial plain was well developed by this period. The conditions were more suitable for human activities because of the reduced landslide frequency and the amelioration of climate.

As known from the archaeological records (Liu 2000; Chen and Chiu 2004), agriculture was already established in the Ilan region from around $700 \mathrm{cal}$ B.P. The sand layer with few pollen grains at the Wuyuan site could be the result of erosion after burning of the forests in the hills. About 400 years age, the sharp decrease in trees and dominance of herbs could be a result of anthropogenic vegetation changes. Significant forest clearance and site occupation occurred in the Ilan region.

\section{Conclusions}

Pollen analysis of the sediments from the past 4200 years from the Ilan Plain, northeastern Taiwan displays a record of environmental changes for the late Holocene. The vegetation changes suggest a shift of environment from coastal to wetland and finally to terrestrial although with a slight time lag between sites.

The pollen record from the Wuyuan site indicates a relatively warm climate prevailed at ca. 4200 cal B.P. Montane forest around the plain was dominated by evergreen, broad-leaved trees. At approximately 3800 to $3200 \mathrm{cal}$ B.P., elements tolerant of brackish water, such as Bruguiera and Acrostichum, dominated the vegetation at the Wuyuan site, indicating a short period of local marine transgression prior to ca. 3800 years ago. Although marine conditions regressed thereafter, the lowland terrain was occupied mainly by marshlands and riverine areas between ca. 3200 and 2250 cal B.P. The occurrence of shells from brackishwater species, together with Myriophyllum and mangrove from the Kiwulan site, probably indicates a fluvial environment near estuaries between ca. 2770 and 2480 cal B.P.
The abundance of Gramineae, Cyperaceae and aquatic plants suggests widespread marshlands between 3200 and $2250 \mathrm{cal}$ B.P. at the Wuyuan site and between 2170 and 1580 cal B.P. at the Kiwulan site. The notable occurrence of Alnus in the Kiwulan profile since about 2250 cal B.P. probably suggests a progressive expansion of Alnus forests accompanied by an episode of frequent landslides in the neighbouring highlands. Chronologically, the flourishing of Alnus coincides approximately with widespread aggradation which led to the development of a series of terraced fans upstream on the Lanyang River between 2150 and 1350 cal B.P. It possibly suggests environmental instability induced by increasing frequency of typhoons or heavy precipitation during this period. By ca. 1300 cal B.P, the occurrence of lowland vegetation such as Cephalanthus and Barringtonia indicates the shift from a marsh to a terrestrial environment in response to drying of the lowlands. The decline of Alnus pollen in the Kiwulan profile probably implies a reduction in the landslide frequency and amelioration of the climate between 1320 and 700 cal B.P.

The pollen records imply a close relationship between the development of prehistoric civilization and environmental changes. The archaeological sites attributed to the Middle Neolithic were mainly located in littoral areas on the Ilan Plain between ca. 4200 and 3800 cal B.P., this being the time when the pollen assemblages indicate a relatively warm climate. However, around 3800 years ago, the settlements in the lowlands were abandoned and re-established on the inland hills surrounding the plain. The pollen record from the Wuyuan site documents a dramatic increase in mangrove and wetland flora that implies a short period of marine transgression. This is then followed by fairly wet and unstable conditions between 3200 and 2250 cal B.P. in the lowland terrain. It is quite conceivable that the dislocation of the population could be due to the changing environment in the lowlands that forced people to migrate to the surrounding hills.

A hiatus in the archaeological records exists between 2400 and 1300 cal B.P. throughout the Ilan region. The combined archaeological and paleoenvironment evidence indicates that the hiatus corresponded to a period of heavy precipitation or frequent typhoons as implied by the abundance of Alnus forests and the development of terraced fans upstream on the Lanyang River. It is reasonable to propose that the persistence of climate deterioration and frequent landslides would have dramatically influenced human activities and led to the inhabitants leaving for other locations.

By ca. 1300 cal B.P., a different clan attributed to the earlier stage of the Iron Age arrived and occupied the riverine areas and coastal dunes of the Ilan Plain. The pollen record implies that the fluvial plain was well developed by this period. The decrease in landslide frequency and the amelioration of climate since ca. 1300 cal B.P. could have been advantageous for human activities. At about 400 years ago, the sharp de- 
crease in trees and the increase in herbs in the pollen records could be related to intensive colonisation of this area. As is known from the archaeological records, agriculture was practiced on a large scale. Significant forest clearance and settlement occurred during the recent past.

Acknowledgments We thank the Central Geological Survey and Prof. Chen Yu-Be for providing samples and $\mathrm{C}^{14}$ dates. We are also grateful for many useful suggestions from Huang Shih-Chiang, Liu TsungKwei, Chen Yu-Be and Chen Min-Te. The critical review by Robert F. Thorne of Rancho Santa Ana Botanic Garden, U.S.A. is greatly appreciated. Thanks are extended to two anonymous reviewers who offered valuable critiques that helped improve the manuscript.

\section{References}

Abbott M, Binford M, Brenner M, Kelts K (1997) A 3,500 14C yr highresolution sediment record of lake level changes in Lake Titicaca, Bolivia/Peru. Quat Res 47:169-180

Binford MW, Kolata AL, Brenner M, Janusek JW, Seddon M, Abbott M, Curtis JH (1997) Climate variation and the rise and fall of an Andean civilization. Quat Res 47:235-248

Bishop P, Penny D, Stark M, Scott M (2003) A 3.5 ka record of paleoenvironments and human occupation at Angkor Borei, Mekong Delta, Southern Cambodia. Geoarchaeol 18:359-393

Chen BL (1996) Geomorphic evolution of alluvial fans in the upper Lanyang valley (in Chinese). Master thesis, University of Taipei

Chen SH, Wang YF (1999) Pollen flora of Yuenyang Lake Nature Preserve, Taiwan (I). Taiwania 44:82-136

Chen TY (2000a) Plant ecology of lowland areas in northern Taiwan (in Chinese). In: Yen HF (ed) Botanical garden resources and its management. National Museum of Natural Science Press, Taichung, pp 9-33

Chen WS (2000b) The study of sediments, depositional environments and stratigraphic correlations in the Lanyang Plain - Report of Groundwater Monitoring Network in Taiwan Plan (in Chinese). Central Geological Survey Press, Taipei

Chen YB, Chiu SJ (2004) Report of salvage excavation on the Kiwulan Site, Yilan County (in Chinese). MTC Taiwan Area National Expressway Engineering Bureau Press, Taipei

Chiang SH (1995) Climatic change in Ilan (in Chinese). In: Chu JT (ed) Proc. Ilan Research Symp. (1). Yilan County Government Press, Ilan, pp 10-35

Chung TF, Huang TC (1972a) Palaeoecological study of Taipei Basin (1), Taipei Botanical Garden. Taiwania 17:117-141

Chung TF, Huang TC (1972b) Palaeoecological study of Taipei Basin (2), Neihu profile. Taiwania 17:239-247

Chung TF, Huang TC, Stamp RB (1973) Paleoecological study of Taiwan (3), The Pu-li Basin. Taiwania 18:179-193

Chyi SJ, Sung QC, Chen BL, Hsieh ML, Tsai H, Fu JK (1998) The evolution of alluvial fans along the upper reach of Lanyang River (in Chinese). Environ Worlds 2:137-150

Compton JS, Franceschini G (2005) Holocene geoarchaeology of the Sixteen Mile Beach barrier dunes in the Western Cape, South Africa. Quat Res 63:99-107

Cullen HM, deMenocal PB, Hemming S (2000) Climate change and the collapse of the Akkadian Empire: evidence from the deep sea. Geology 28:379-382.

Curtis JH, Hodell DA, Brenner M (1996) Climate variability on the Yucatan Peninsula (Mexico) during the past 3500 years, and implications for Maya cultural evolution. Quat Res 46:37-47
deMenocal PB (2001) Cultural responses to climate change during the late Holocene. Science 292:667-673

Grimm EC (2004, 2005) TILIA and TGView software. Ver 2.0.2. Illinois State University, Illinois

Grosjean M, Nunez L, Cartajena I, Messerli B (1997) Mid-Holocene climate and culture change in the Atacama Desert, northern Chile. Quat Res 48:239-246

Hodell DA, Curtis JH, Brenner M (1995) Possible role of climate in the collapse of Classic Maya civilization. Nature 375:391-394

Hoelzmann P, Keding B, Berke H, Kropelin S, Kruse HJ (2001) Environmental change and archaeology: lake evolution and human occupation in the Eastern Sahara during the Holocene. Palaeogeogr Palaeoclimatol Palaeoecol 169:193-217

Hsieh CL (1984) Surveys of mangrove in Kaohsiung Bay (in Chinese). Kaohsiung-wen-xian 18/19:251-268

Huang SC (1998) Report of survey and excavation for cultural sites form Toucheng to Suao, Taipei to Ilan Freeway (in Chinese). MTC Taiwan Area National Expressway Engineering Bureau Press, Taipei

Huang TC (1972) Pollen Flora of Taiwan. Botany Department NTU, Taipei

Huang TC (1975) Paleoecological study of Taiwan (4) - Waichaitaoken profile. Taiwania 20:1-22

Huang TC (1981) Spore Flora of Taiwan. Botany Department NTU, Taipei

Huang SY, Huang TC (1977a) Palaeoecological study of Taiwan (5) Toushe Basin. Taiwania 22:1-14

Huang TC, Huang SY (1977b) Paleoecological study of Taiwan (7) Pollen analysis of Yueh Tan (in Chinese). Bulletin Experimental Forest NTU 120:185-196

Huang TC, Tsang CH (1976) Paleoecological study of Taiwan (6) - Pollen analysis of Pre-historic archeological sites of Shih-BaChang, Ta-Chiu-Yuan, Niu-Ma-Tou, and Tsao-Shieh-Tun (in Chinese). Bulletin Departement of Anthropology 39-40:91-115

Huang TC, et al. (1993-2003) Flora of Taiwan, 2nd ed., vol 1 (1994); vol 2 (1996); vol 3 (1993); vol 4 (1998); vol 5 (2000); vol 6 (2003). Botany Department NTU, Taipei

Kuo Chen-Meng (1993) Plant ecology of Dongshan He and Lanyang Chi (in Chinese). Yilan County Government Press, Ilan

Kuo Chen-Meng (2001) An introduction to ferns (in Chinese). YuanLiou Press, Taipei

Kuo Chen-Meng (1994) Pollen analysis of lake sediments in the Toshe Basin since older than $10 \mathrm{Ka}$ (in Chinese). Master thesis, University of Taipei

Kuo Chen-Meng, Liew PM (2000) Vegetational history and climatic fluctuations based on pollen analysis of the Toushe peat bog, central Taiwan since the last Glacial Maximum. J Geol Soc China 43:379-392

Letouzey J, Kimura M (1986) The Okinawa trough genesis, structure and evolution of the backarc basin developed in a continent. Mar Petr Geol 2:111-130

Liew PM, Chung NJ (2001) Vertical migration of forests during the last glacial period in subtropical Taiwan. West Pac Earth Sci 1:405414

Liew PM, Hsieh ML (2000) Late Holocene (2 ka) sea level, river discharge and climate interrelationship in the Taiwan region. $\mathrm{J}$ Asian Earth Sci 18:499-505

Liew PM, Huang SY (1994) A 5000-year pollen record from Chitsai Lake, Central Taiwan. Terrestrial Atmos Oceanic Sci 5:411419

Liew PM, Huang CY, Tseng MH (1997) Preliminary study on the late Quaternary climatic environment of the Taipei Basin and its possible relation to basin sediments. J Geol Soc China 40:17-30

Liew PM, Kuo CM, Huang SY, Tseng MH (1998) Vegetation change and terrestrial carbon storage of eastern Asia during the last glacial maximum as indicated by new pollen records of northern Taiwan. Global Planet Change 16:85-94 
Liu CC (1995a) The Ilan Plain and the southwestward extending Okinawa Trough. J Geol Soc China 38:229-242

Liu YC (1995b) Prehistoric culture type of Ilan region (in Chinese). In: Chu JT (ed) Proc Ilan Research Symp (1). Yilan County Government Press, Ilan, pp 38-56

Liu YC (2000) The importance of Ilan archaeology in Taiwan (in Chinese). I-Lan J Hist 43:3-27

Liu YC, Chiu SJ, Dai RC, Wang MY, Li CY (2001) Report of salvage excavation on the Tachuwei Site, Yilan County (in Chinese). Yilan County Government Press, Ilan

Liu YC, Chiu SJ, Dai RC, Li CY, Liao CS (2002) Report of salvage excavation on the Wanshan Site, Yilan County (in Chinese). Yilan County Government Press, Ilan

Moore PD, Webb JA, Collinson ME (1991) Pollen analysis, 2nd ed. Blackwell, London

Ortloff C, Kolata A (1993) Climate and collapse: agro-ecological perspectives on the decline of the Tiwanaku state. J Archaeol Sci 20:195-221

Pederson DC, Peteet DM, Kurdyla D, Guilderson T (2005) Medieval Warming, Little Ice Age, and European impact on the environment during the last millennium in the lower Hudson Valley, New York, USA. Quat Res 63:238-249

Polyak VJ, Asmerom Y (2001) Late Holocene climate and cultural changes in the Southwestern United States. Science 294:148-151

Shimada I, Schaaf CB, Thompson LG, Mosley-Thompson E (1991) Cultural impacts of severe droughts in the prehistoric Andes: application of a 1,500-year ice core precipitation record. World $\mathrm{Ar}-$ chaeol 22:247-270

Stanley DJ, Chen Z, Song J (1999) Inundation, sea-level rise and transition from Neolithic to Bronze Age Cultures, Yangtze Delta, China. Geoarchaeol 14:15-26

Stuiver M, Reimer PJ, Bard E, Beck JW, Burr GS, Hughen KA, Kromer B, McCormac G, Van Der Plicht J, Spurk M (1998) INTCAL98 Radiocarbon Age Calibration, 24000-0 cal B.P. Radiocarbon 40:1041-1083
Su HJ (1984) Studies on the climate and vegetation types of the natural forests in Taiwan (II) - altitudinal vegetation zones in relation to temperature gradient. Quart J Chin Forestry 17:57-73

Suppe J (1984) Kinematics of arc-continent collision, flipping of subduction, and back-arc spreading near Taiwan. Memoir Geol Soc China 6:21-33

Thanikaimoni G (1987) Mangrove palynology. Sri Aurobindo Ashram Press, Pondicherry, India

Tsukada M (1966) Late Pleistocene vegetation and climate in Taiwan (Formosa). Proc Nat Acad Sci USA 55:543-548

Tsukada M (1967) Vegetation in subtropical Formosa during the Pleistocene glaciations and the Holocene. Palaeogeogr Palaeoclimatol Palaeoecol 3:49-64

Weiss H, Bradley RS (2001) What drives societal collapse? Science 291:609-610.

Weiss H, Courty MA, Wetterstrom W, Guichard F, Senior R, Meadow A (1993) The genesis and collapse of third millennium North Mesopotamian civilization. Science 261:995-1004

Wu WX, Liu TS (2004) Possible role of the "Holocene Event 3" on the collapse of Neolithic Cultures around the Central Plain of China. Quat Internat 117:153-166

Yasuda Y, Fujiki T, Nasu H, Kato M, Morita Y, Mori Y, Kanehara M, Toyama S, Yano A, Okuno M, Jiejun H, Ishihara S, Kitagawa H, Fukusawa H, Naruse T (2004) Environmental archaeology at the Chengtoushan site, Hunan Province, China, and implications for environmental change and the rise and fall of the Yangtze River civilization. Quat Internat 123-125:149-158

Yeh YH, Lin CH, Roecker SW (1989) A study of upper crustal structures beneath northeastern Taiwan: possible evidence of the western extension of Okinawa Trough. Proc Geol Soc China 32:139156

Yu S, Zhu C, Song J, Qu W (2000) Role of climate in the rise and fall of Neolithic cultures on the Yangtze Delta. Boreas 29:157165 